\title{
PREFACE
}

Dear Reader, we are delighted to present the autumn issue of the UCL Journal of Law and Jurisprudence. This issue distinguishes itself through the relevance of its themes, the rigour and depth of the research undertaken, and the clarity of the ideas presented. We believe these qualities reflect the spirit of the Journal as an inclusive yet aspirational legal publication.

In the first article, Ailsa McNeil examines the impact of austerity on access to justice. McNeil's significant contribution details how austerity measures undertaken by recent UK governments have had a particularly deleterious effect for women. In the second article, Mario Guido analyses private prison labour. In doing so, Guido challenges the traditional distinction between public and private interests and questions how far the privatisation of the criminal justice system should go. In our third piece, Joseph Mahon situates the application of the 1951 Refugee Convention against contemporary disquiet surrounding global terrorism. In particular, Mahon's fascinating piece discusses the denial of refugee protection to those suspected of serious crimes.

The next three articles explore important issues at the intersection of law and economics: financial regulation, competition, and the relationship between business and human rights. Conor Duffin-Hall, presenting a germane critique of the intellectual underpinnings of modern finance theory, questions whether the lessons from the 2008 financial crisis have been incorporated into the post-crisis regulatory framework. Richard Tepper investigates the impact of two landmark decisions issued by the Court of Justice of the European Union in the field of competition law in the pharmaceutical sector: Servier and Others v European Commission and H. Lundbeck A/S and Lundbeck Ltd v European Commission. In our final piece, Aleydis Nissen undertakes an in-depth analysis of the rules aiming to enhance transparency in the oil, gas, mining and logging sectors, and discusses the issues associated with tax avoidance and corruption in countries rich in natural resources.

Naturally, we are tremendously grateful to the six authors who feature in this edition of the UCL Journal of Law and Jurisprudence. The effort involved in bringing submissions to publication is far from insignificant and we thank the authors for their diligence. We hope they are as happy as we are to see their work in print. Additionally, we would like to thank all others who submitted their work for consideration by the Editorial Board; the Journal thrives when we are fortunate enough to select from a competitive field, and this was certainly the case with the present issue. 
We also wish to express our gratitude to our Board members, both LLM students and PhD researchers, who reviewed submissions in the first instance. The Journal maintains a strict commitment to blind peer review and we simply could not operate without the efforts of the Board. Of course, we owe an even greater debt to those committed members who worked with the authors to bring to light the best version of the pieces featured in this edition.

We are very thankful for the ongoing support that we receive from Dr Daniela Simone, our Faculty Editor, who is always prompt in assisting us with her advice and suggestions. We also thank Professor Alex Mills for writing the foreword to this issue. We also want to extend our thanks to those whose names do not appear in the pages of the Journal but without whose help the Journal could not come into being. Consequently, we thank the teams at UCL Press and UCL Discovery for their kind support and advice, as well as staff within UCL Laws who support us with the essential administrative work related to the running of the Journal.

Lastly, as is tradition at the start of the academic year, we are pleased to introduce the new leadership of the Journal for 2019/20: Sarah Davies, Sonam Gordhan and Thomas Papadogiannis Varouchakis. We have been truly privileged to preside over the Journal and promote it as a space for critical thinking and innovative scholarship. We are confident Sarah, Sonam and Thomas will enjoy the experience and we look forward to seeing the Journal improve in their hands.

Joyman Lee \& Andrew McLean

Academic Editors

\section{Luminita Olteanu}

Managing Editor 